\title{
Study of the AISI 52100 Steel Reuse Through the Powder Metallurgy Route Using High Energy Ball Milling
}

\author{
Bruna Horta Bastos Kuffner ${ }^{a *}$, Gilbert Silva ${ }^{a}$, Carlos Alberto Rodrigues ${ }^{a}$, Geovani Rodrigues ${ }^{a}$ \\ aInstituto de Mecânica - IEM, Universidade Federal de Itajubá - UNIFEI, Av. BPS, 1303, CEP 37500- \\ 903, Itajubá, MG, Brasil.
}

Received: June 03, 2017; Revised: September 19, 2017; Accepted: October 05, 2017

\begin{abstract}
The AISI 52100 is a tool steel used in industry to produce bearings. After the end of its life cycle, it is remelted or discarded in deposits. The powder metallurgy rises as an alternative to recycle this material without any waste. The steps used to produce the AISI 52100 steel by powder metallurgy included: Machining with speed of $45 \mathrm{rpm}$, high energy ball milling of the scraps during 30 hours with mass/sphere relation of 1:15 and speed of $400 \mathrm{rpm}$, uniaxial pressing using $175 \mathrm{MPa}$ and sintering through 30 minutes at $1200^{\circ} \mathrm{C}$. Also, were incorporated $1 \%, 3 \%$ and $5 \%$ of alumina particles in the milling process to increase the milling efficiency and mechanical strength after sintering. The results of microstructural and mechanical analysis indicated that the alumina addition during the milling process increased the AISI 52100 steel properties, being 3\% the percentage proved as the most efficient among all additions.
\end{abstract}

Keywords: AISI 52100 steel, alumina, powder metallurgy, high energy ball milling.

\section{Introduction}

The tool steels represent a significant segment of the market of special steels, because of its excellent mechanical properties associated with relative low cost. Normally, they are used in industry as cutting tools, molds and die fabrication, due its high dimensional stability and mechanical strength at high temperatures. This is possible because of the large amount of carbon and alloying elements in its composition, as $\mathrm{Cr}, \mathrm{Mn}, \mathrm{Si}, \mathrm{Cu}, \mathrm{Ni}, \mathrm{Mo}^{1}$.

The AISI 52100 is a tool steel widely used in mechanical components, as extrusion tools and bearings. It is often requested in applications that demand high wear resistance and contact fatigue ${ }^{2,3}$. During the manufacturing process, the AISI 52100 is melted in electric furnace and forged or hot rolled, being posteriorly submitted to heat treatment. Its microstructure can be spheroidized (ferritic matrix and chromium carbides), quenched (martensitic matrix) or annealed (matrix of cementite and pearlite). The most important properties of the AISI 52100 steel include density of $7,81 \mathrm{~g} / \mathrm{cm}^{3}$, elastic modulus of $210 \mathrm{GPa}$ and hardness of $207 \mathrm{HV}$ (spheroidized), $848 \mathrm{HV}$ (quenched) or $210 \mathrm{HV}$ (annealed) $)^{4,5}$. Its chemical composition is $\mathrm{C}(0.93-1.05), \mathrm{Cr}$ (1.35-1.60), $\mathrm{Mn}(0.25-0.45), \mathrm{Si}(0.15-0.35), \mathrm{Cu}(0-0.30), \mathrm{Ni}$ (0-0.25), Mo (0-1.1), P (0-0.025) and S $(0-0.015)^{6}$.

At the end of its life cycle, the mechanical components produced with AISI 52100 steel are usually remelted or discarded in deposits, which generates great amount of environmental pollution. One possible method to reuse these components is the powder metallurgy. This route allows the

*e-mail: brunakuffner@hotmail.com production of materials with complex geometries, various compositions to serve several applications and practically no waste. Also, it is proved as an economic route for the production of workpieces in large scale. The powder metallurgy includes the steps of powders obtainment (atomization, electrolysis, hydrogenation or milling), pressing (uniaxial, isostatic or hot isostatic) and sintering (in inert or vacuum atmosphere) $)^{7,8}$.

Among all the current milling techniques, the high energy ball milling proved to be effective in the production of metallic powders. Due the high impact created by the milling spheres submitted to high rotation speeds and impact frequency, it is possible to obtain submicrometer and nanometric particles after advanced milling times. This technique has been used for many years for mechanical alloying, but only recently as a milling method. The difference between them is that in the mechanical alloying, the particles of the materials are reduced through the high impact with the milling spheres, leading the smaller particles of the reinforcement to be trapped in the matrix, forming thus, a composite or alloy. In the mechanical milling, the powders only have their particles size reduced through the impact with the milling spheres, and the main intention of the procedure is not to create an alloy or composite, but reduce the particles size ${ }^{9,10}$.

Between all of the types of composites produced using the powder metallurgy with high energy ball milling, the metal-matrix composites (MMCs) are considered one of the most produced composites, once that it can ally the great ductile properties of the metal and the high hardness and temperature properties of the ceramic particles. With this, is possible to create a material not only with better performance than its forerunners, but also, produce products that are very 
difficult to produce by the conventional melting processes. In general, it is possible to highlight as the most important properties of MMCs the high wear and corrosion resistance. However, the properties obtained in the final product will depend not exclusively of the matrix and reinforcement properties, but also of the particles size and bonding between the elements of the $\mathrm{MMC}^{11,12}$.

The use of ceramic particles during the milling process of metallic materials MMCs is well-known, due its capacity to reduce more efficiently the metallic particles, especially during the initial milling times, where the cold hardening takes more time to start to show its efficiency. This occurs because the ceramic particle is very hard and causes a tension region when it collides with ductile particle, leading to fragmentation. Another expected property of the ceramic addition during the milling process is the obtainment of a sintered material that possess higher hardness and wear resistance, in comparison with the pure metallic material after sintering ${ }^{13-15}$.

Besides the effects induced due the high hardness of its particles, the alumina can also develop the ability to difficult the dislocations movement when dispersed in the steel matrix, but only if it presents particles located in nanometric scale. The particles located in submicrometer scale act restrictively as grain growth inhibitors. Although the use of ceramic nanoparticles to reinforce metallic matrix is desirable, these particles present a tendency to agglomerate and form clusters, which is considered a problem. Thus, it is always indicated to control the granulometry of the powders before sintering ${ }^{16}$.

Althought several authors in the literature studied the microstructural and mechanical properties of metal-matrix composites produced through the powder metallurgy route using high energy ball milling ${ }^{10-12,16-19}$, specific researches about the AISI 52100 steel with alumina additions were not found. Thus, this work aims to evaluate the microstructural and mechanical behaviour of this steel processed by these routes with different percentages of alumina additions.

\section{Materials and Methods}

The materials used in this study were: A billet of AISI 52100 steel from the hot rolling process, with diameter of $50.8 \mathrm{~mm}$ and length of $200 \mathrm{~mm}$, and alumina powder from the calcination process with medium particles size of $10 \mu \mathrm{m}$.

To the obtainment of the scraps which would be posteriorly milled, the billet of the AISI 52100 steel was submitted to a machining process with $45 \mathrm{rpm}$ of rotation and absence of lubricating oil to avoid contamination. The thickness arbitrated was $1 \mathrm{~mm}$.

After the machining process, 120 grams of scraps were divided in 4 milling vases of a Noah-Nuoya ${ }^{\circledR}$ NQM $0.2 \mathrm{~L}$ high energy ball mill. To increase the milling efficiency, 3 milling vases of the AISI 52100 steel were processed with
$1 \%, 3 \%$ and $5 \%$ of alumina addition, remaining only one vase without this addition, as a reference parameter. The different percentages were used to determine which one would present better results. The parameters used in the milling process are described in Table 1.

Table 1. Parameters used in the AISI 52100 steel milling process

\begin{tabular}{cc}
\hline Milling parameter & Value \\
\hline Speed & $400 \mathrm{rpm}$ \\
Mass/sphere relation & $1: 15$ \\
Time & $5,10,20$ and 30 hours \\
Downtime & 15 minutes/hour \\
\hline
\end{tabular}

At the end of the milling process, the powder with the best alumina condition and the reference powder without alumina addition were pressed uniaxially in a cylindrical matrix with $12 \mathrm{~mm}$ of diameter and $175 \mathrm{MPa}$ of pressure being posteriorly sintered at $1200^{\circ} \mathrm{C}$, during 30 minutes with $20^{\circ} \mathrm{C} / \mathrm{min}$ of heating rate. The furnace used was a Fortelab ${ }^{\circledR}$ with inert atmosphere of argon. By the end of the process, were confectioned 8 samples for each condition, totalizing 16 samples.

The powders and the sintered samples were analyzed microstructurally and mechanically. A Microtrac ${ }^{\circledR}$ laser granulometer was used analyze the particles size after the milling process. A Carl Zeiss ${ }^{\circledR}$ Evo MA 15 scanning electron microscope was used in the secondary electron (SE), backscattered electron (BSD) and energy dispersive $\mathrm{x}$-ray (EDX) modes to identify the particles variation, morphology, alumina location in the steel matrix and present phases in the sintered steel. To evaluate the porosity, hardness and elastic modulus through compressive strength, respectively, were used an Olympus ${ }^{\circledR}$ BX41M optical microscope, an Emco $^{\circledR}$ M4R 075 durometer and an EMIC ${ }^{\circledR}$ DL universal testing machine. The compressive strength test followed the parameters described in the ASTM E9-09. The identification of the present phases and the analysis of the amorphization of the powders after the high energy ball milling process were made using a Panalytical ${ }^{\circledR} X^{\prime}$ Pert PRO x-ray diffractometer with the help of the HighScore ${ }^{\circledR}$ software $^{20}$.

\section{Results and Discussion}

\subsection{Powders analysis}

The Figure 1 shows the scraps of the AISI 52100 steel milled through 5 hours. It is possible to observe that the steel milled pure (with $0 \%$ of alumina addition) (Figure 1a) presented acicular morphology after the process, and particles size located in a range of $500 \mu \mathrm{m}$ to $70 \mu \mathrm{m}$. With $1 \%, 3 \%$ and $5 \%$ of alumina addition, the predominant morphology of the AISI 52100 steel particles was flaky, and the size were located in a range of $330 \mu \mathrm{m}$ to $30 \mu \mathrm{m}$ for $1 \%$ of alumina 

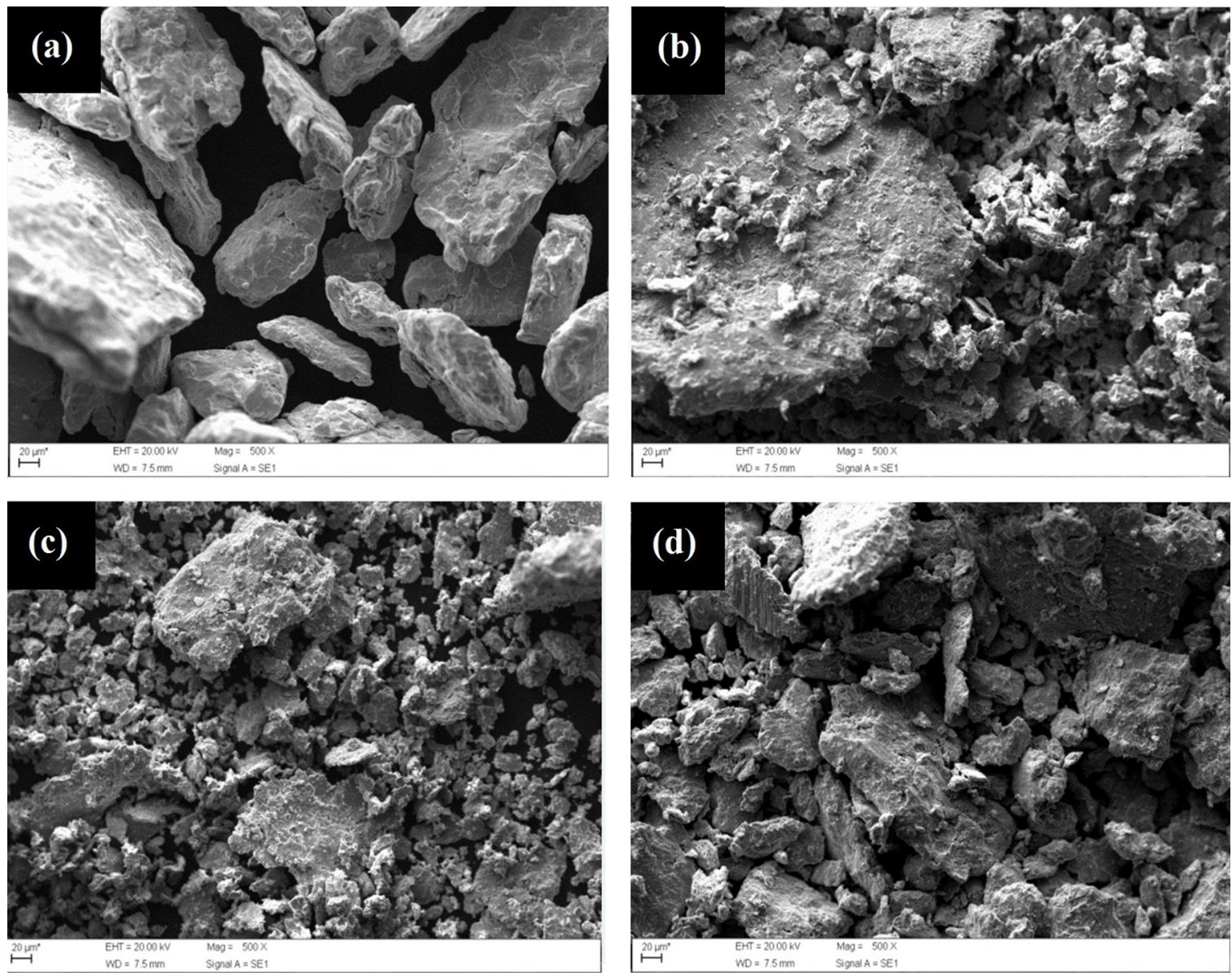

Figure 1. SEM of the AISI 52100 steel milled through 5 hours with (a) $0 \%$ of alumina (b) $1 \%$ of alumina (c) $3 \%$ of alumina (d) $5 \%$ of alumina

addition (Figure $1 \mathrm{~b}$ ), $180 \mu \mathrm{m}$ to $20 \mu \mathrm{m}$ for $3 \%$ of alumina addition (Figure 1c) and $230 \mu \mathrm{m}$ to $30 \mu \mathrm{m}$ for $5 \%$ of alumina addition (Figure 1d). In these conditions, the formation of clusters was observed only in the compositions with $3 \%$ of alumina addition.

Continuing the milling process to 10 hours, it is observed in Figure 2 that all the compositions presented particles with irregular morphology, differently from those obtained with 5 hours (Figure 1). The particles size was located in a range of $70 \mu \mathrm{m}$ to $15 \mu \mathrm{m}$ in the pure steel (Figure 2a), 30 $\mu \mathrm{m}$ to $5 \mu \mathrm{m}$ in the steel with $1 \%$ of alumina (Figure $2 \mathrm{~b}$ ), $30 \mu \mathrm{m}$ to $3 \mu \mathrm{m}$ in the steel with $3 \%$ of alumina (Figure $2 \mathrm{c}$ ) and $30 \mu \mathrm{m}$ to $5 \mu \mathrm{m}$ in the steel with $5 \%$ of alumina (Figure $2 d)$. The reduction in the particles size from 5 hours to 10 hours of milling was significant. With 3\% of alumina, was observed clusters formation, since it was the addition that presented lower particles size.

Increasing the milling time from 10 to 20 hours, it is observed that the particles morphology did not suffer modification (Figure 3). The pure steel presented medium particle size between $15 \mu \mathrm{m}$ and $2 \mu \mathrm{m}$ (Figure 3a), between $20 \mu \mathrm{m}$ and $1 \mu \mathrm{m}$ with $1 \%$ of alumina (Figure $3 \mathrm{~b}$ ), between 5 $\mu \mathrm{m}$ and $1 \mu \mathrm{m}$ with $3 \%$ of alumina (Figure $3 \mathrm{c}$ ) and between $10 \mu \mathrm{m}$ and $5 \mu \mathrm{m}$ with $5 \%$ of alumina. For all the additions, was observed clusters formation, due the reduced particles size of the powders milled through 20 hours. The composition with $3 \%$ of alumina continued to present the smallest particle size among all the studied percentages.

With 30 hours of milling (Figure 4), was observed that the particles maintained the irregular morphology for all of the alumina additions. The particles size for this milling time was located in a range between $10 \mu \mathrm{m}$ and $5 \mu \mathrm{m}$ to the pure steel (Figure 4a), between $10 \mu \mathrm{m}$ and $5 \mu \mathrm{m}$ to the steel with $1 \%$ of alumina (Figure $4 \mathrm{~b}$ ), between $5 \mu \mathrm{m}$ and $0.5 \mu \mathrm{m}$ to the steel with $3 \%$ of alumina (Figure $4 \mathrm{c}$ ), and finally, between $10 \mu \mathrm{m}$ and $5 \mu \mathrm{m}$ to the steel with $5 \%$ of alumina. The results indicated that, through SEM analysis was possible to observe a few nanoparticles for the composition with $3 \%$ of alumina, differently from the other compositions which presented particles only in submicrometer scale. The formation of clusters occurred in all of the conditions, being more pronounced in the composition with $3 \%$ of alumina. Authors like ${ }^{10-12,16-19}$ also observed the tendency that the milling process of metallic powders with alumina addition 

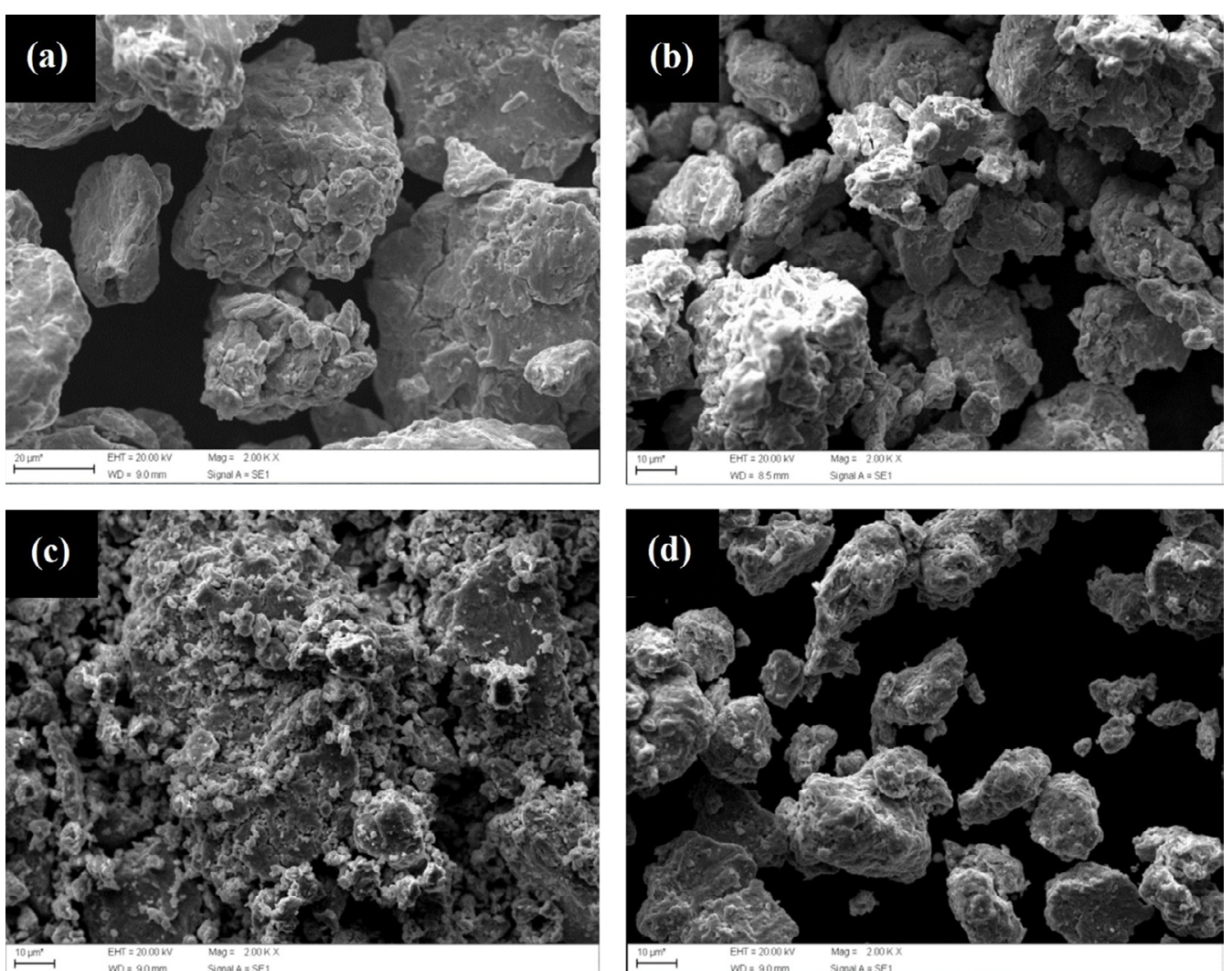

Figure 2. SEM of the AISI 52100 steel milled through 10 hours with (a) $0 \%$ of alumina (b) $1 \%$ of alumina (c) $3 \%$ of alumina (d) $5 \%$ of alumina
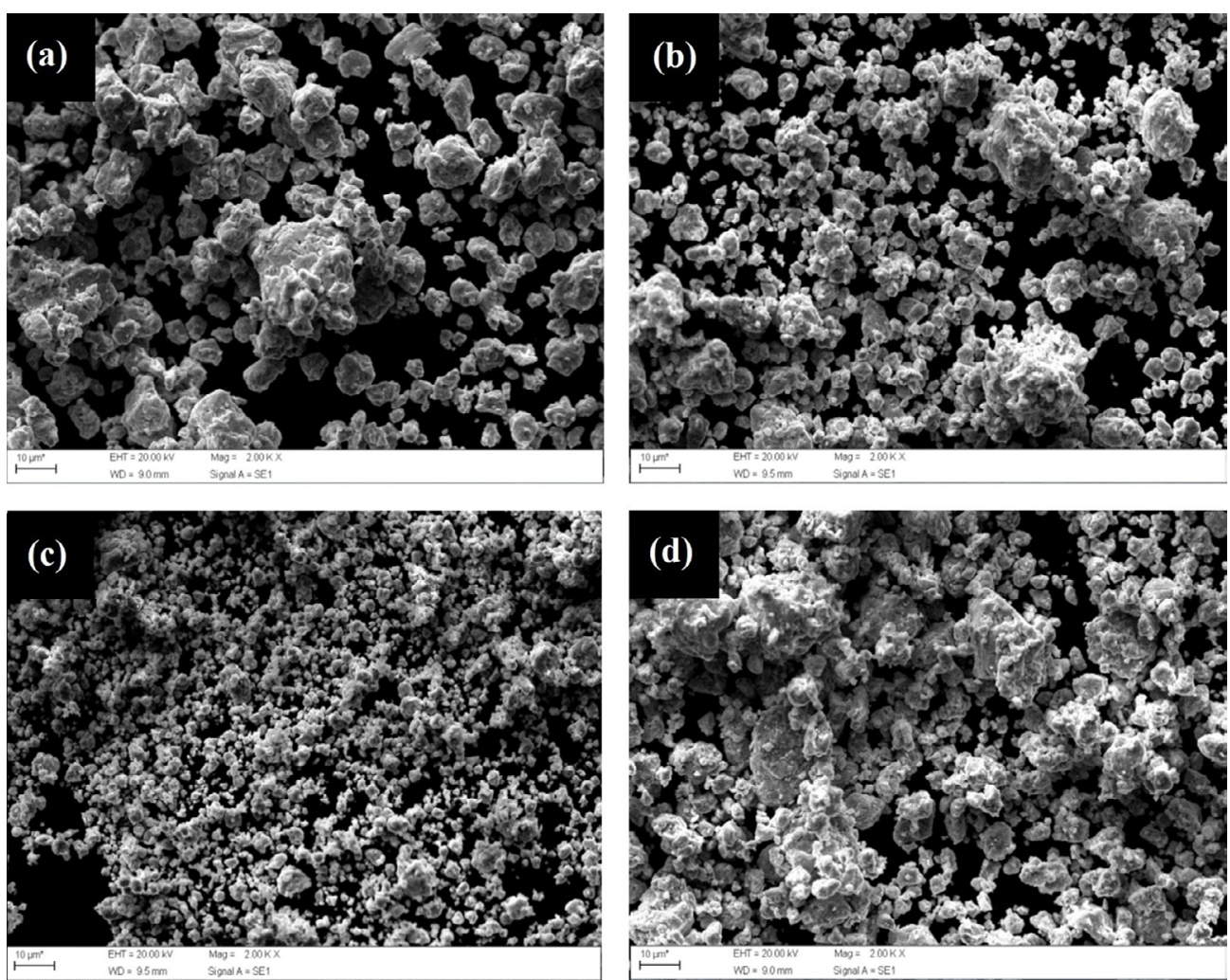

Figure 3. SEM of the AISI 52100 steel milled through 20 hours with (a) $0 \%$ of alumina (b) $1 \%$ of alumina (c) $3 \%$ of alumina (d) $5 \%$ of alumina 

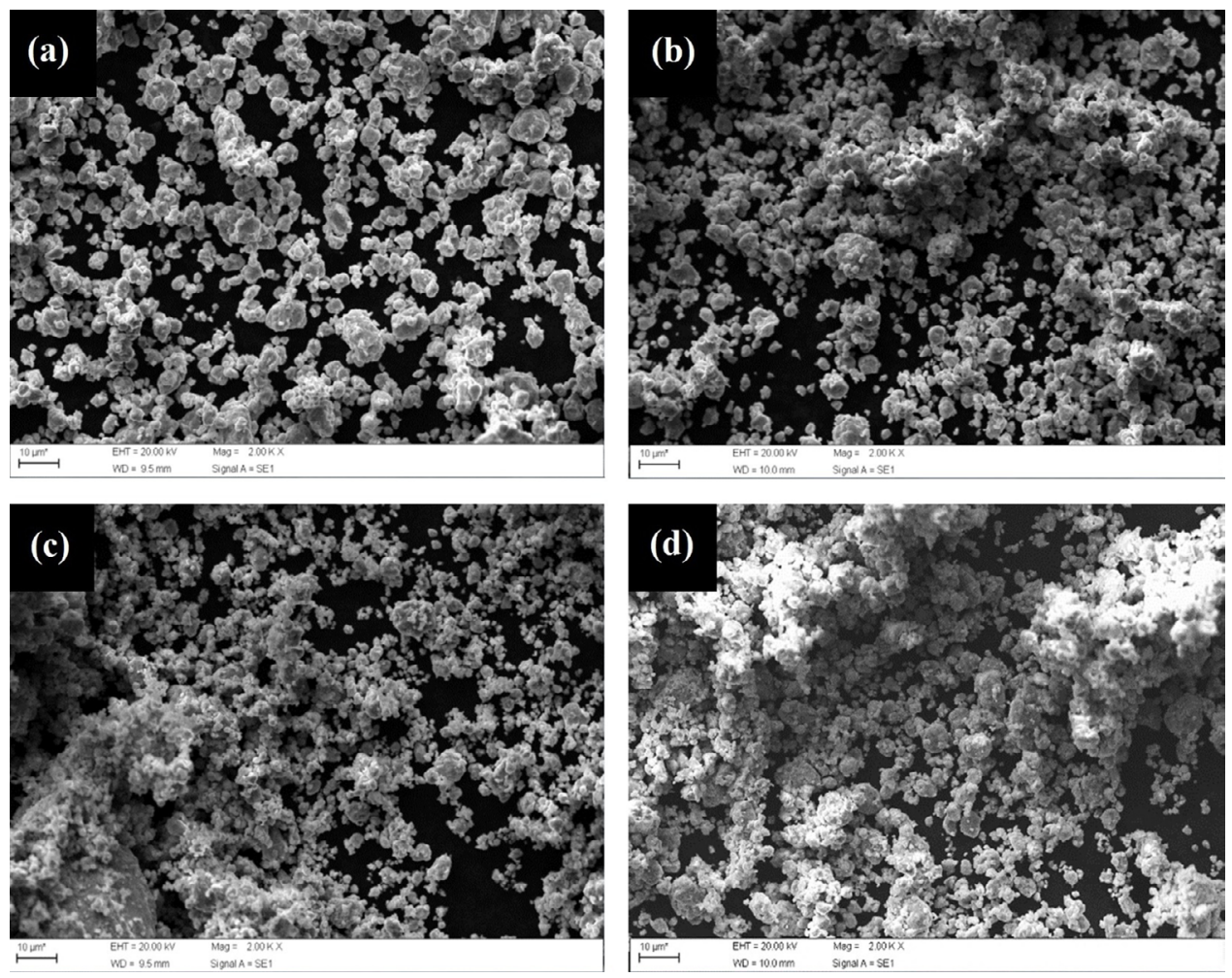

Figure 4. SEM of the AISI 52100 steel milled through 30 hours with (a) $0 \%$ of alumina (b) $1 \%$ of alumina (c) $3 \%$ of alumina (d) $5 \%$ of alumina

have to generate clusters. It happens due to the high energy involved during the milling process and the cold-welding phenomena.

The Figure 5 shows the graph obtained through laser granulometry that relates the particles size in function of the milling times for each alumina addition. It is possible to observe again that the steel milled with $3 \%$ of alumina showed more efficiency in the process than the other compositions, since as like in the SEM, it presented smaller particles size and higher volume of particles in submicrometer scale.

The Figure 6 shows the $\mathrm{x}$-ray diffraction analysis for the powders after 5 and 30 hours of milling. Comparing the diffractograms obtained after 5 hours of milling with those obtained after 30 hours of milling, it is observed that the peaks of the powders with 30 hours presented enlargement and a greater reduction in their height in comparison with the diffractograms of the powders obtained with 5 hours, which presented narrower and higher peaks. It occurs due the amorphization of the crystalline structure of the powders during the milling process, which was more pronounced after 30 hours of milling time. The amorphization happens as a result of the high energy ball milling, which is a very aggressive process that induces high deformation over the particles, and consequently, destruction of their crystalline structure. It is also observed in the Figure 6 that the diffractograms did not show the presence of the alumina phase. It happens due to the small percentage of alumina

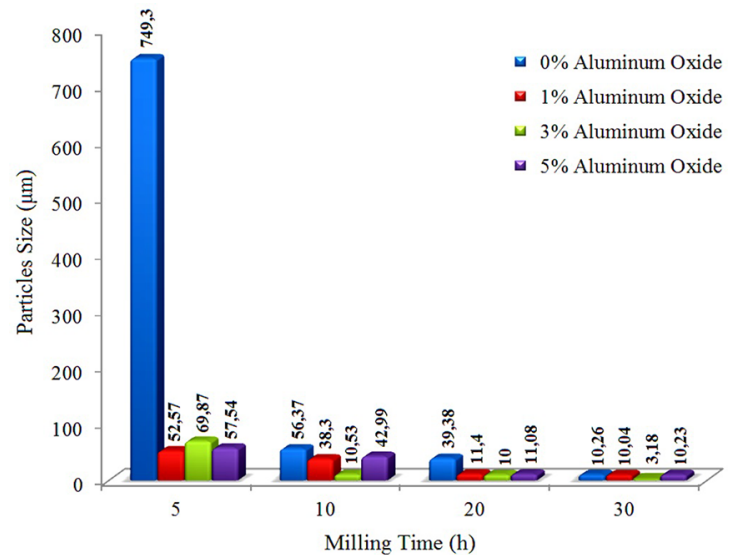

Figure 5. Particles of higher volumetric fraction versus milling time

that was added to the powder. Other authors as ${ }^{10-12,16,18,19}$ also investigated the effect that extending the milling times generates in the crystalline structure of MMCs composed by metallic powders and alumina. The studies attested that, by increasing the milling times, the amorphization phenomena continued to happens. With this, was possible to estimate that, in certain moment of the milling process, the material could become amorphous, due the complete destruction of its crystalline structure.

The crystallite size was calculated using the Scherrer method and also proves that the powders suffered amorphization 

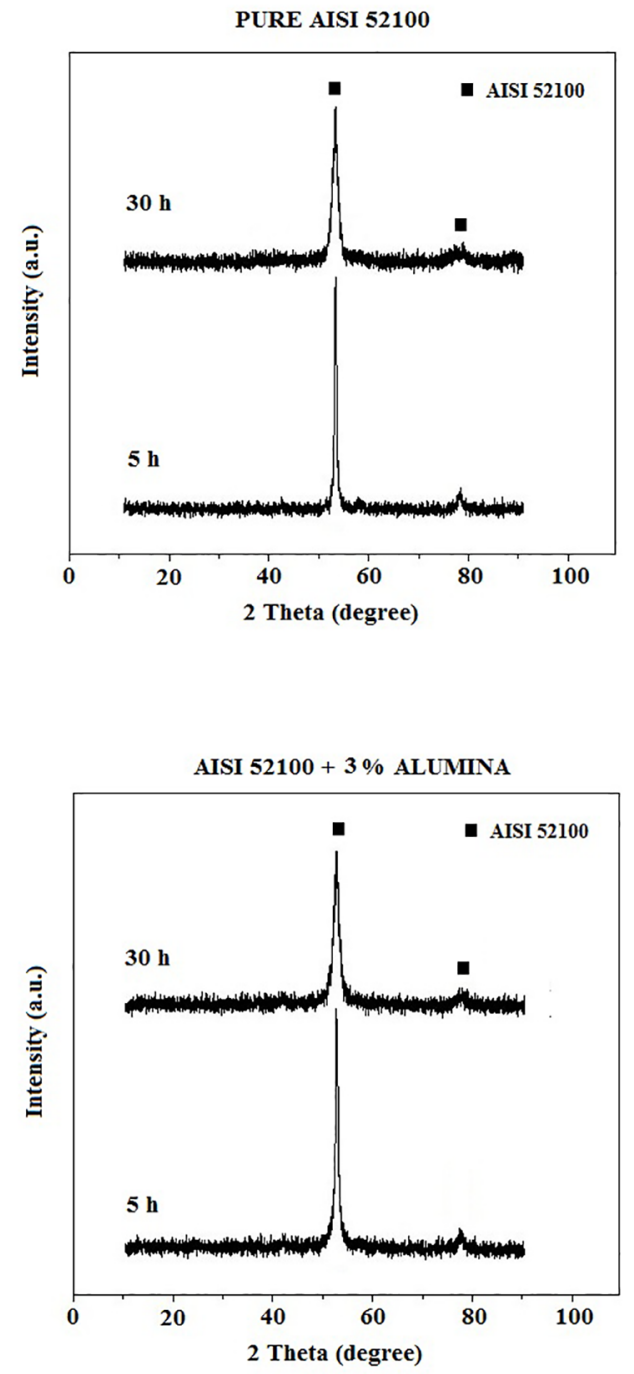
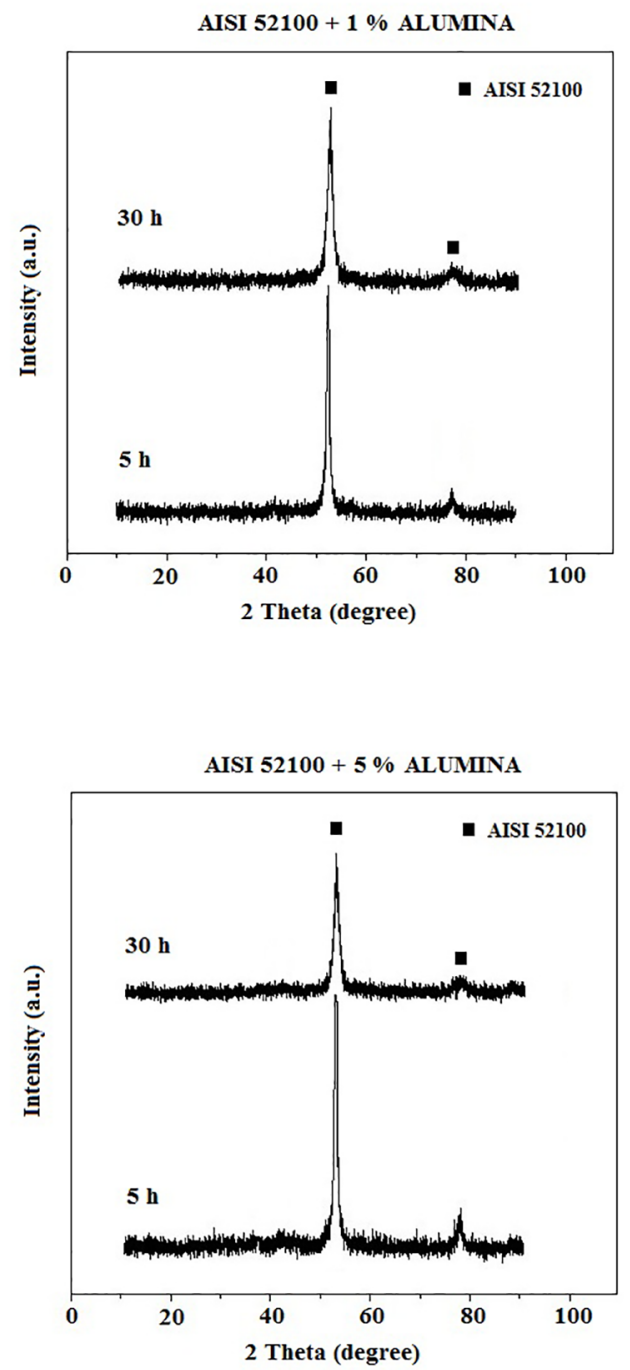

Figure 6. Amorphization analysis via x-ray diffraction after high energy ball milling for all of the conditions

during the milling process. The pure steel presented crystallite size of $23 \mathrm{~nm}$ after 5 hours of milling which decreased to 8.5 $\mathrm{nm}$ after 30 hours. The steel with $1 \%$ of alumina presented size of $19 \mathrm{~nm}$ after 5 hours of milling and $9 \mathrm{~nm}$ after 30 hours. With $3 \%$ of alumina, the powder presented crystallite size of $17 \mathrm{~nm}$ after 5 hours of milling and $8 \mathrm{~nm}$ after 30 hours. Lastly, the steel with $5 \%$ of alumina presented $22 \mathrm{~nm}$ of crystallite size after 5 hours of milling and $9 \mathrm{~nm}$ after 30 hours. With this, is possible to observe that for all of the compositions, the powders presented reduction in their crystallite size, which proves their amorphization due the gradual destruction of the crystalline structure of the steel.

Analyzing the powders in terms morphology, was observed that the particles presented differentiation during the milling process. With 5 hours, the morphology predominant was acicular for the pure steel and flaky for percentages of $1 \%, 3 \%$ and $5 \%$ of alumina. Over 10 hours, the morphology changed and was maintained as irregular for all the alumina additions.

Although the morphology was maintained as the same for all the composition, the evolution in the particles size was differentiated. The composition with $3 \%$ of alumina and 30 hours of milling presented nanoparticles, which was not proved in other conditions. The presence of small particles as nanoparticles is considered very important to decrease the porosity of sintered samples and increase its mechanical resistance.

In general, the high energy ball milling process was proved as effective route to reduce the AISI 52100 steel, since that 
starting from scraps, was possible to obtain powders. All of the alumina additions increased significantly the efficiency of the process, especially in the first 5 hours, were is observed that the AISI 52100 steel milled with alumina achieved higher volume of particles size in a range of $50-70 \mu \mathrm{m}$, while the steel milled pure achieved higher volume of particles size with $750 \mu \mathrm{m}$. It represents an average of $450 \%$ smaller particles size for the compositions with alumina in the initial 5 hours of milling in comparison with the steel milled pure. For times starting from 10 hours, the compositions with alumina maintained higher volumetric fraction in the range $10 \mu \mathrm{m}$, while the steel milled pure achieve this granulometry only in advanced milling times (30 hours).

The higher reduction observed in the scraps of the AISI 52100 steel with $1 \%, 3 \%$ and $5 \%$ of alumina in comparison with the steel milled pure is attributed to the formation of a ductile-brittle milling system. According to ${ }^{9}$, it happens once that, during the process, the submicrometer particles of the alumina get confined in the interlamellar spacings of the steel (which possesses higher size than the alumina). It induces over the ductile particle a zone of stress concentration, as a consequence of the high hardness of the brittle ceramic particle which suffers with the impact of the milling spheres that are submitted under high rotation speed. Thus, the steel milled under the ductile-brittle system pass through the work hardening process much faster than the steel milled pure, were the work hardening happens only through the action of the impact between the ductile particles and the milling spheres. This effect was observed as more pronounced in the initial 5 hours of the AISI 52100 steel milling.

It is also verified in the Figure 5 that, even though the percentage of $3 \%$ of alumina was shown as the most efficient starting from 10 hours of milling, in the first 5 hours it was presented as the worst alumina condition. It happened because, as we could see in Figure 1, the particles of this composition started to form clusters from 5 hours of milling, which did not happen in the other composition. Starting from 10 hours of milling, it is observed the formation of clusters for all the compositions. It occurs due the reduced granulometry of the particles that tent to agglomerate over each other, in consequence of the high stresses inherent of the high energy ball milling process.

As it was observed in the Figure 5, the powder obtained with 30 hours of milling time and $3 \%$ of alumina presented the smaller particles size among all of the alumina additions and milling times. With this, it was chosen to be pressed, sintered and mechanically evaluated, together with the reference powder without alumina.

The analysis of the powder with $3 \%$ of alumina and 30 hours of milling time via SEM in the EDX mode determined the alumina dispersion in the surface of the powder (Figure 7). In the Figure $7 \mathrm{a}$, was possible to identify the chemical elements ( $\mathrm{C}, \mathrm{Cr}$ and $\mathrm{Fe}$ ) from the AISI 52100 constitution and the presence of $\mathrm{Al}$, which is not a chemical element present in the steel chemical composition. The presence of this element is attributed to the addition of the alumina during the milling process of the AISI 52100 steel. In addition, it is observed in the Figure $7 \mathrm{~b}$ the good distribution of the alumina particles over the AISI 52100 steel powder.

\subsection{Sintered samples analysis}

The densification of the sintered samples is directly associated with their mechanical properties. The value found for the density of the composition without alumina was of $5.40 \mathrm{~g} / \mathrm{cm}^{3}$, and for the composition with $3 \%$ of alumina, $5.30 \mathrm{~g} / \mathrm{cm}^{3}$. It is possible to observe that the alumina addition does not affect significantly the density values after the sintering process, due the small percentage of this addition. In comparison with the AISI 52100 steel from the casting process, the steel produced by the powder metallurgy route obtained density $31 \%$ lower than the casted steel (7.81 g/ $\mathrm{cm}^{3}$ ). The standard deviation found was of 0.15 for the pure samples and of 0.30 for the samples with $3 \%$ of alumina.
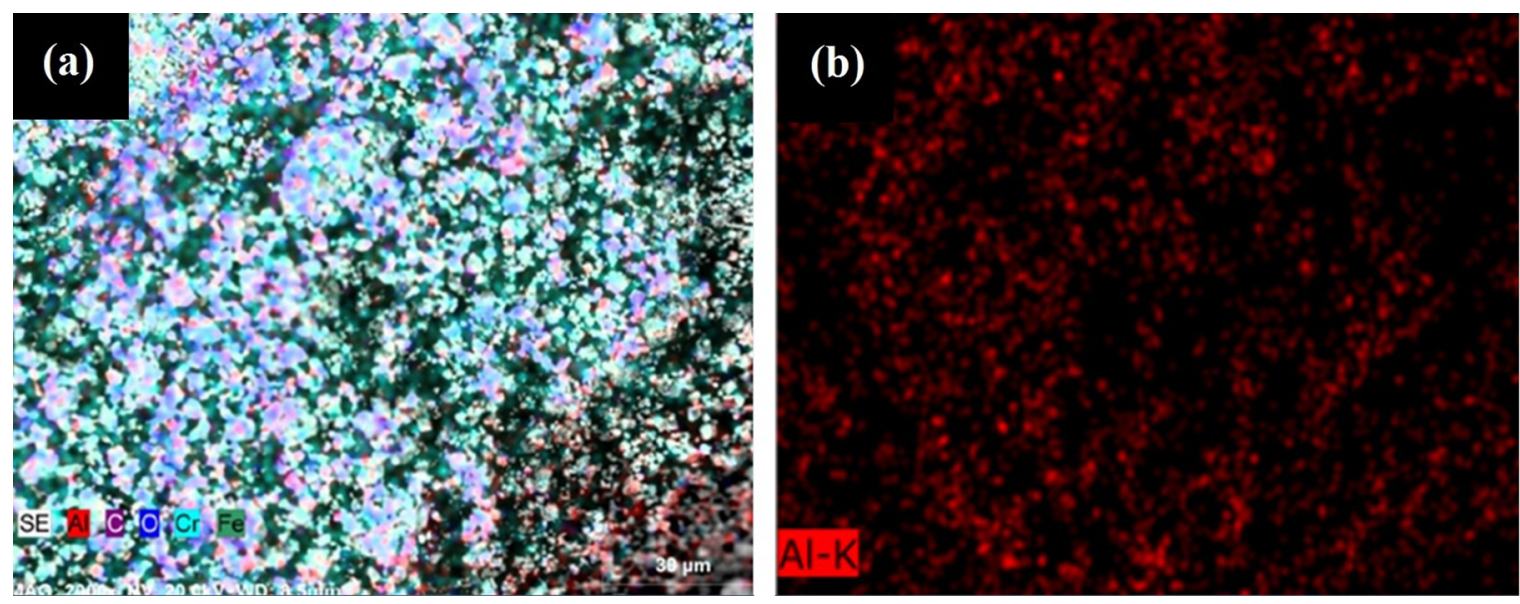

Figure 7. Mapping of the AISI 52100 steel with $3 \%$ of alumina (a) Mainly chemical elements of the AISI 52100 steel (b) Alumina particles dispersion 
The Figure 8 shows the concentration of pores in the samples pure and with $3 \%$ of alumina. The red spots represent the pores, while the white spots represent the sintered AISI 52100 steel. In the pure steel, was observed a value of porosity corresponding to $14 \%$ (Figure 8 a) while with $3 \%$ of alumina, a porosity of $9 \%$ (Figure $8 b$ ). It represents a reduction of $35 \%$ in the porosity of the samples produced with alumina. Also, is observed the better distribution of the porosity in the samples with alumina in comparison with the pure samples. In this analysis, the standard deviation was of 2.36 for the pure samples and 1.65 for the samples with alumina.

The mechanical properties of the AISI 52100 steel produced through the powder metallurgy route were evaluated by the tests of hardness and compressive strength. The pure steel presented hardness of $60 \mathrm{HV}$ and elastic modulus of $1.8 \mathrm{GPa}$, while the samples with $3 \%$ of alumina presented hardness of $70 \mathrm{HV}$ and elastic modulus of $2.5 \mathrm{GPa}$.

According with these results, it is possible to observe a decrease in the hardness values of $71.5 \%$ for the pure steel and of $66.7 \%$ for the steel with $3 \%$ of alumina, in comparison with the hardness value obtained in the AISI 52100 steel from the casting process as annealed $(210 \mathrm{HV})$. Also, comparing the elastic modulus of the AISI 52100 steels produced by powder metallurgy with the casted steel (210 $\mathrm{GPa}$ ), it is possible to observe a decrease of $99.5 \%$ in the elastic modulus of the pure steel and of $98.81 \%$ in the steel with alumina. The standard deviation found for the hardness was of 4.5 in the pure steel and of 7.9 in the steel with 3\% of alumina. By the same way, the standard deviation for the elastic modulus corresponded to 0.038 for the pure samples and 0.021 for the sample with $3 \%$ of alumina.

The most important parameter that influenced the better results of porosity and consequently, mechanical properties of the AISI 52100 steel milled with $3 \%$ of alumina in comparison with the AISI 52100 steel milled pure, was the granulometry of the particles after the milling process. The powder of the steel with $3 \%$ of alumina addition presented smaller particles size at the end of the milling process. With this, during the uniaxial pressing, the compaction of these samples was better than the compaction of the pure steel. As a consequence of the better compaction, the samples produced with alumina presented less porosity. Since the sintering process in the solid state happens through the action of atomic diffusion, the samples with less porosity presented more contact between their particles, which increased the densification after the sintering. Another factor that contributed to the better sintering of the samples with alumina is the physical effect that these particles have over the steel particles. The submicrometer particles of alumina are considered incoherent precipitates that can inhibit the grain growth during the thermal treatment, when located in the grain boundaries ${ }^{9,21,22}$.

In general, the authors ${ }^{10-12,16-19}$ also observed that, increasing the milling times, the properties of the MMCs composed by a metallic matrix and alumina as reinforcement achieved better results of density, porosity, hardness and elastic modulus, due to the factors discussed during this work.

The Figure 9 shows the microstructural analysis of the AISI 52100 steel via SEM. It is possible to observe that its microstructure is constituted by a ferritic matrix, a $(\mathrm{FeCr})_{3} \mathrm{C}$ phase and pores. The ferritic matrix and the $(\mathrm{FeCr})_{3} \mathrm{C}$ phase are identified, respectively, as light and dark regions, while the black regions correspond to the pores. Through chemical analysis via EDX, was possible to prove that the light region is composed by the chemical element Iron, which represents a ferritic matrix. In the dark region, were found the chemical elements Iron, Chromium and Carbon, which correspond to a $(\mathrm{FeCr})_{3} \mathrm{C}$ phase that precipitated during the sintering process. The $(\mathrm{FeCr})_{3} \mathrm{C}$ phase precipitates instead of the usual cementite due the tendency that the chromium has to bond with the cementite during the sintering process ${ }^{23}$.
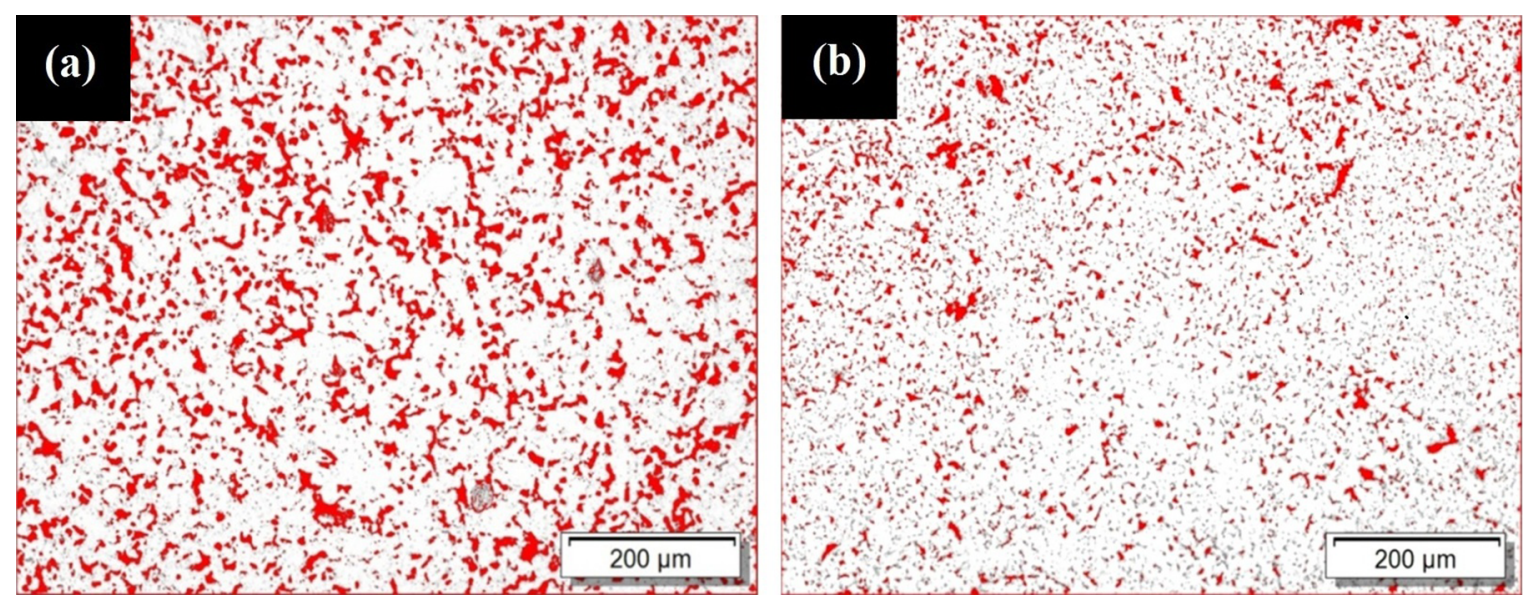

Figure 8. Porosity analysis of the AISI 52100 steel (a) Pure (b) With $3 \%$ of alumina 


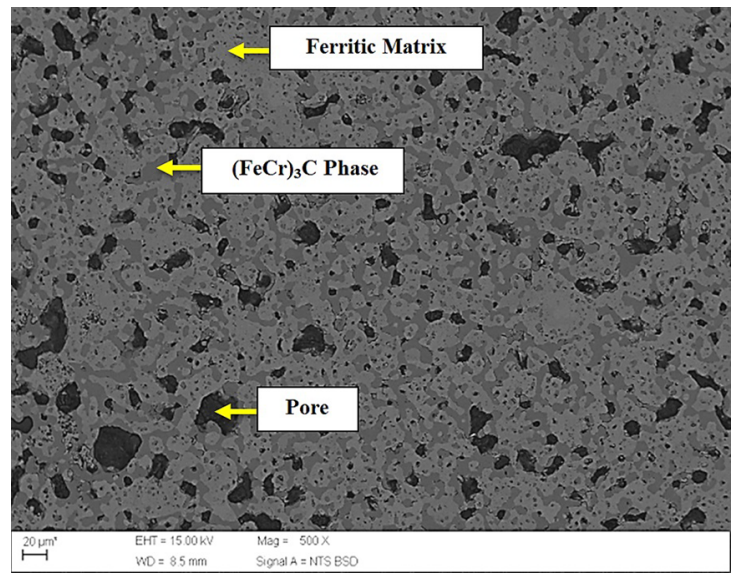

Figure 9. SEM of the AISI 52100 steel showing its microstructure

\section{Conclusions}

The powder metallurgy was shown as an efficient route to reuse the AISI 52100 steel scraps and produce a new product. The powders obtained from the high energy ball milling presented high volume of particles in submicrometer scale, which is considered an advantage to obtain samples with high densification. The alumina addition was proved as efficient to facilitate the reduction of the AISI 52100 steel particles in all of the milling times, but especially in the initial 5 hours of milling, when the work hardening process is slower. Among all of the alumina additions studied in this work, the $3 \%$ was showed as the most effective percentage to enhance the milling efficiency. As a result, the sintered samples of this condition presented better densification and mechanical properties.

\section{Acknowledgements}

The authors would like to thank the FAPEMIG for financing this research and the company ALCOA from Poços de Caldas - MG for the alumina donation.

\section{References}

1. Tanski T, Labisz K, Brytan Z, Jonda E, Sroka M. Thermal Fatigue Influence of Laser Treated Tool Steel Surface. Procedia Engineering. 2014;74:429-442.

2. Jimenez-Melero E, Blondé R, Sherif MY, Honkimäki V, Van Dijk NH. Time-dependent synchrotron X-ray diffraction on the austenite decomposition kinetics in SAE 52100 bearing steel at elevated temperatures under tensile stress. Acta Materialia. 2013;61(4):1154-1166.

3. Rahbar-kelishami A, Abdollah-zadeh A, Hadavi MM, Seraj RA, Gerlich AP. Improvement of wear resistance of sprayed layer on 52100 steel by friction stir processing. Applied Surface Science. 2014;316:501-507.

4. Bhadeshia HKDH. Steels for bearings. Progress in Materials Science. 2012;57(2):268-435.
5. Xie J, Alpas AT, Northwood DO. The role of heat treatment on the erosion-corrosion behavior of AISI 52100 steel. Materials Science and Engineering: A. 2005;393(1-2):42-50.

6. ASTM International. ASTM A295- 98 - Standard specification for high-carbon anti-friction bearing steel. West Conshohocken: ASTM International; 1998.

7. Mahesh K, Sankaran S, Venugopal P. Microstructural Characterization and Mechanical Properties of Powder Metallurgy Dual Phase Steel Preforms. Journal of Materials Science \& Technology. 2012;28(12):1085-1094.

8. Narasimhan KS. Recent advances in ferrous powder metallurgy. Advanced Performance Materials. 1996;3(1):7-27.

9. Suryanarayana C. Mechanical alloying and milling. Progress in Materials Science. 2001;46(1-2):1-184.

10. Ozdemir I, Ahrens S, Mücklich SM, Wielage B. Nanocrystalline $\mathrm{Al}-\mathrm{Al}_{2} \mathrm{O}_{3 \mathrm{p}}$ and $\mathrm{SiC}_{\mathrm{p}}$ composites produced by high-energy ball milling. Journal of Materials Processing Technology. 2008;205(1-3):111-118.

11. Zawrah MF, Zayed HA, Essawy RA, Nassar AH, Taha MA. Preparation by mechanical alloying, characterization and sintering of $\mathrm{Cu}-20$ wt. $\% \mathrm{Al}_{2} \mathrm{O}_{3}$ nanocomposites. Materials \& Design. 2013;46:485-490.

12. Ahamed H, Senthilkumar V. Role of nano-size reinforcement and milling on the synthesis of nano-crystalline aluminium alloy composites by mechanical alloying. Journal of Alloys and Compounds. 2010;505(2):772-782.

13. Scamans GM, Birbilis N, Buchheit RG. Corrosion of aluminum and its alloys. Shreir's Corrosion. 2010;3:1974-2010.

14. Lach R, Haberko K, Bucko MM, Szumera M, Grabowski G. Ceramic matrix composites in the alumina/5-30 vol.\% YAG system. Journal of the European Ceramic Society. 2011;31(10):1889-1895.

15. Dörre E, Hübner HW. Alumina - Processing, Properties and Applications. $1^{\text {st }}$ ed. New York: Springer-Verlag; 1984.

16. Afkham Y, Khosroshahi RA, Mousavian RT, Brabazon D, Kheirifard R. Microstructural characterization of ball-milled metal matrix nanocomposites $(\mathrm{Cr}, \mathrm{Ni}, \mathrm{Ti})-25$ wt.\% $\left(\mathrm{Al}_{2} \mathrm{O}_{3 n \mathrm{p}}\right.$, $\left.\mathrm{SiC}_{\mathrm{np}}\right)$. Particulate Science and Technology. 2016:1-12.

17. Alizadeh M, Aliabadi MM. Synthesis behavior of nanocrystalline $\mathrm{Al}-\mathrm{Al}_{2} \mathrm{O}_{3}$ composite during low time mechanical milling process. Journal of Alloys and Compounds. 2011;509(15):4978-4986.

18. Afkham Y, Khosroshahi RA, Kheirifard R, Mousavian RT, Brabazon D. Microstructure and morphological study of ballmilled metal matrix nanocomposites. Physics of Metals and Metallography. 2017;118(8):749-758.

19. Salahi E, Rajabi A. Fabrication and characterisation of copperalumina nanocomposites prepared by high energy fast milling. Journal of Materials Science and Technology. 2016;32(12):12121217.

20. ASTM International. ASTM E9 - 09 - Standard Test Methods of Compression Testing of Metallic Materials at Room Temperature. West Conshohocken: ASTM International; 2009.

21. Spriggs GE. A history of fine grained hardmetal. International Journal of Refractory Metals and Hard Materials. 1995;13(5):241255. 
22. Hamano R. The effect of the precipitation of coherent and incoherent precipitates on the ductility and toughness of highstrength steel. Metallurgical Transactions A. 1993;24(1):127-139.
23. Beswick JM. The effect of chromium in high carbon bearing steels. Metallurgical Transactions A. 1987;18(11):1897-1906. 